\title{
ARE Bioequivalents ReAlly EqUAL?: GENERIC Substitution IN THE CONTEXT OF MENTAL ILLNESS
}

\author{
Jaymes V. Fairfax-Columbo and David DeMatteo*
}

\begin{abstract}
Generic drugs are significantly less expensive than their brand name counterparts, and the use of generic drugs has increased drastically in recent years, representing upwards of $75 \%$ of all prescriptions filled in the United States. A large amount of this increase is due to states' adoptions of generic substitution laws, or laws that allow for the substitution of generic drug formulations in place of their brand name counterparts. Theoretically, generic drugs are just as effective as their brand name alternatives; in fact, the FDA requires that generic formulations demonstrate "bioequivalence," meaning that they show absorption rates of active ingredients that are within a range of $80-125 \%$ of that of brand name drugs. Despite their theoretical equivalence, generic and brand name drugs can produce disparate results and side effects. This is problematic when states employ substitution schemes in which no notification of either the physician or patient is necessary for the pharmacist to substitute, and is especially problematic when these conditions are met and substitution is mandated. This problem may be exacerbated for individuals with chronic mental illness, where reduced effectiveness of generic medications can produce individually and societally detrimental outcomes and where differential side effects might interfere with already poor medication compliance rates. This Article examines the effectiveness of generic versus brand name drug formulations in terms of treating mental illness, discusses possible implications of their

** Jaymes Fairfax-Columbo is a J.D./Ph.D. student in the Drexel University School of Law and College of Arts and Sciences; JD expected 2019, PhD expected 2020; B.A., Swarthmore College. David DeMatteo, J.D., Ph.D., is an Associate Professor of Psychology and Law at Drexel University, where he is also Director of the J.D./Ph.D. Program in Law and Psychology.
\end{abstract}


differential effectiveness, and proposes several solutions for policy change to combat these issues.

I. INTRODUCTION .283

II. GENERIC DRUGS AND SUBSTITUTION: DEFINITION, STANDARDS, AND APPROACHES 287

A. Generic Drugs: What are They? 287

B. State Approaches to Generic Substitution. 288

III. SCIENTIFIC Issues With GeNERIC SubSTITUTION ........290

A. The Limits of Pharmacokinetic Studies ....................290

B. Bioequivalence: Do Generic Drugs Really Produce the

Same Effects as Brand Names?.... 293

IV. GENERIC Substitution AND MENTAL IlLnEss .... 295

A. How Effective are Generics at Treating Mental Illness? 296

1. Bipolar Disorders. 296

2. Anxiety Disorders 299

3. Major Depressive Disorder. 302

4. Schizophrenia and Psychotic Disorders. 304 B. Benefits and Detriments of Generic Substitution of Medications for Consumers........................................306 C. Why Should We Care? ........................................... 307

1. Mental Health Disorders as Chronic Disorders ......308

2. Medication Adherence. 309

3. Patient Autonomy: The Right to Medical Decision Making..... 310

4. Seemingly Overlooked Problems: Criminal Culpability and Pharmacist Liability.... .316 5. Limitation of Remedies for Persons Injured by Generic Psychotropics and Competitor Liability

V. What SHould We Do?

A. Eliminate Mandatory Generic Substitution 322

B. Notification and Consent 322

C. Education. 323

D. At the Very Least, Employ the Above Proposals for

Psychotropic Drugs.

VI. CONCLUSION 


\section{INTRODUCTION}

In March 2008, Andrew Richards was sitting in front of his television when he collapsed suddenly, stating that he felt as if he had been hit with a bolt of lightning. ${ }^{1}$ While Richards was indeed felled by electricity, it did not come in the form of lightning; rather, it came in the form of abnormal electrical activity in his brain-in other words, a seizure. ${ }^{2}$ Richards, who suffers from depressive symptoms, contends that his seizure was the result of generic substitution, or the process of his pharmacist switching him from a 300 milligram $(\mathrm{mg})$ prescription of Wellbutrin XL, a brand name antidepressant, to a generic version of the drug manufactured by Teva Pharmaceuticals USA. ${ }^{3}$ Richards indicated that immediately following the switch he began to experience "jolts and jerks," and that while he and Teva came to a settlement in the civil suit that followed his seizure, he still experiences spasms and other lingering effects associated with the episode. ${ }^{4}$

While Richards' "jolts and jerks" may have been warning signs of an impending seizure, in reality warning signs regarding the potential deleterious effects of Teva's generic had existed for over a year prior to his attack. ${ }^{5}$ In

${ }^{1}$ Charles Seife \& Rob Garver, No Substitute: When a Generic Drug Isn't What it Seems, PropublicA (Apr. 15, 2013, 8:17 AM), http://www.propublica.org/article/no-substitute-when-a-generic-drugisnt-what-it-seems, archived at http://perma.cc/VA6Y-WWT5.

2 Id. Seizures are caused by abnormal electrical activity in the brain, either on one side of the brain (focal seizure), or on both sides (generalized seizure). U.S. Nat'l Inst. of Health, Seizures, NLM/NIH, http://www.nlm.nih.gov/medlineplus/seizures.html (last visited Mar. 19, 2015).

${ }^{3}$ Seife \& Garver, supra note 1. Generic substitution is the process by which a generic drug is substituted for a prescribed brand name drug; both the generic drug and the brand name drug have the same active ingredient. John Posner \& John P. Griffin, Generic Substitution, 72 Brit. J. Clinical Pharmacology 731, 731 (2011). It is possible to switch from one form of a generic medication to another, particularly when patients switch to a pharmacy with a different generic supplier than their previous pharmacy. Paul E. Greenberg, Does Generic Substitution Always Make Sense?, 11 J. MED. Econ. 547, 548-49 (2008).

${ }^{4}$ Seife \& Garver, supra note 1.

${ }^{5}$ Id. 
December 2006, the United States Food and Drug Administration (FDA) approved the first generic versions of Wellbutrin XL. ${ }^{6}$ The generic came in two strengths, $150 \mathrm{mg}$ and $300 \mathrm{mg}^{7}$ Within weeks of the release, consumer complaints about diminished effectiveness and negative side effects started pouring in. ${ }^{8}$ Initially, the FDA brushed off the complaints, stating its belief that the drugs were equivalent and turning the perceived disparity back on the consumer, indicating that perhaps the consumers' mental illness was the root of the perceived difference, not the actual effectiveness of the drug itself. ${ }^{9}$

Though the FDA gave the $300 \mathrm{mg}$ generic its endorsement, skepticism over the drug's "equivalence" did not subside. ${ }^{10}$ Alarmed at the sheer number of complaints he was receiving about the generic, People's Pharmacy founder Joe Graedon reached out to independent testing group Consumer Lab and asked it to evaluate the equivalence of the generic to Wellbutrin XL $300 \mathrm{mg} .{ }^{11}$ Consumer Lab's results indicated that while the active ingredient in the two drugs was identical, the rate at which the ingredient was released differed tremendously. ${ }^{12}$ Within two hours the generic had released $34 \%$ of the active ingredient compared to $8 \%$ for its brand name counterpart, and within four hours the generic had released almost $50 \%$

${ }^{6}$ Angel Reyes III, Generic Wellbutrin XL Antidepressant Recall, REYES L. BLOG (Jul. 02, 2013), http://reyeslaw.com/blog/genericwellbutrin-xl-antidepressant-recall/, archived at http://perma.cc/XY6XLK7E.

${ }^{7} I d$.

8 Id. For an example of complaints, see Joe Graedon \& Terry Graedon, Side Effects of Generic Wellbutrin, The People's PhaRMacy (Apr. 23, 2007), http://www.peoplespharmacy.com/2007/04/23/sideeffects-of/, archived at http://perma.cc/EXX7-XSNW.

${ }^{9}$ David Maris, A Drug Recall that Should Frighten US All About the

FDA, FORBES (Oct. 10, 2012, 3:00 PM), http://www.forbes.com/sites/davidmaris/2012/10/10/fda-recall-points-toserious-problems-at-the-fda/, archived at http://perma.cc/2K68-ML9N.

${ }^{10} \mathrm{Liz}$ Neporent, FDA Asks for Voluntary Recall of Popular Generic Antidepressant, ABC NEws (Oct. 4, 2012), http://abcnews.go.com/Health/fda-finds-generic-antidepressantoriginal/story?id=17399399, archived at http://perma.cc/BP2H-KW5V.

${ }^{11} \mathrm{Id}$. (People's Pharmacy is a popular consumer advocacy group.)

$12 I d$. 
of the active ingredient versus just $25 \%$ for Wellbutrin XL. ${ }^{13}$ In effect, the generic functioned more like an immediaterelease drug as opposed to the extended-release product it was advertised to be. ${ }^{14}$

Armed with these findings, Graedon confronted the FDA, requesting the generic's bioequivalence testing data. ${ }^{15}$ Unfortunately, the FDA could provide no such information; in fact, it informed Graedon that the only bioequivalence testing that generic Wellbutrin XL had been subjected to was on its $150 \mathrm{mg}$ dose-the FDA had merely extrapolated those results to the $300 \mathrm{mg}$ dose and assumed it was also bioequivalent. ${ }^{16}$ Subsequent to this admission, the FDA commissioned a bioequivalence study for the $300 \mathrm{mg}$ dose. ${ }^{17}$ Results were not encouraging, and indicated that compared to the extended-release Wellbutrin XL $300 \mathrm{mg}$, the generic did not deliver the active ingredient at the same rate and to the same extent to be considered bioequivalent. ${ }^{18}$ On October 3, 2012, approximately five years after the initial complaints started rolling in, the FDA issued a press release stating that Wellbutrin XL $300 \mathrm{mg}$ and Teva's generic version were not therapeutically equivalent. 19 The

\footnotetext{
${ }_{13} I d$.

${ }_{14} I d$.

${ }^{15} I d$.

16 Bob Pollock, Back in the Headlines-FDA Updates Bioequivalence of Buproprion Extended-Release 300mg Tables, LACHMAN CONSULTANTS (Oct. 11, 2013), http://www.lachmanconsultants.com/back-in-the-headlines-fda-updatesbioequivalence-of-bupropion-extended-release-300mg-tablets.asp, archived at http://perma.cc/THG4-ENVS.

17 Neporent, supra note 10.

18 QUESTIONS AND ANSWERS REGARDING MARKET WITHDRAWAL OF BUDEPRION XL 300 MG MANUFACTURED BY IMPAX AND MARKETED BY TEVA, U.S. Food and Drug Admin., HTTP://WWW.FDA.GOV/DRUGS/DRUGSAFETY/POSTMARKETDRUGSAFETYINF ORMATIONFORPATIENTSANDPROVIDERS/UCM322160.HTM\#Q8, ARCHIVED ATHTTP://PERMA.CC/2JGL-YFT8 (LAST UPDATED OCT. 3, 2012).

19 FDA Update: Budeprion XL $300 \mathrm{mg}$ Not Therapeutically Equivalent to Wellbutrin XL $300 \mathrm{mg}$, U.S. FoOD \& DrUg AdMIN. (Oct. 10, 2013),

http://www.fda.gov/drugs/drugsafety/postmarketdrugsafetyinformatio nforpatientsandproviders/ucm322161.htm, archived at http://perma.cc/57KF-LWBQ. As of October 10, 2013, the FDA, having
} 
FDA then retracted its approval of the generic, prompting Teva to voluntarily withdraw the drug from the market. ${ }^{20}$

The above example is an extreme case-theoretically, bioequivalence testing before generic drugs enter the market should weed out future similar cases. However, the underlying message is the same: just because drugs feature the same and similar amounts of an active ingredient, it is not necessarily ensured that the drugs will perform equivalently. This Article argues that, in general, and at least as regards psychotropic medications, or medications designed to treat and manage the symptoms of mental health disorders, generic substitution schemes that do not provide for notification or consent of either patients or their doctors are misguided. Part II provides an overview of generic substitution and outlines the different ways that states approach it. Part III discusses scientific issues with generic substitution, exploring the limits of pharmacokinetic studies and the theory of bioequivalence. Part IV examines the efficacy and effectiveness ${ }^{21}$ in treating four major categories of mental illness, considers the benefits and detriments of generic substitution for consumers, and discusses treatment and legal issues that are particular to substituting psychotropic medications. Lastly, Part V proffers several solutions for policy change

asked pharmaceutical companies producing generic versions of Wellbutrin XL 300mg to carry out bioequivalence studies, has determined that three of the four producers, Actavis, Inc., Mylan, Inc., and Par Pharmaceuticals satisfied bioequivalence standards but one, Watson, did not. As a result, Watson has withdrawn its product from the market. See Update: Bupropion Hydrochloride Extended-Release $300 \mathrm{mg}$ Bioequivalence Studies, U.S. FOOD \& DRUG ADMIN. (Oct. 10, 2013), http://www.fda.gov/drugs/drugsafety/postmarketdrugsafetyinformationfor patientsandproviders/ucm322161.htm, archived at http://perma.cc/73ULJUUG.

20 FDA Update: Budeprion XL $300 \mathrm{mg}$ Not Therapeutically Equivalent to Wellbutrin XL $300 \mathrm{mg}$, supra note 19.

21 "Efficacy" refers to the performance of an intervention (here, medication) under controlled and ideal circumstances, whereas "effectiveness" refers to the performance of a medication under "real world" conditions. Amit. G. Singal, A Primer on Effectiveness and Efficacy Trials, 5 Clinical Translational Gastroenterology 1, 1 (2014). 
designed to help mitigate the various concerns outlined in the rest of the Article, including eliminating mandatory substitution, eliminating substitution without consent, and providing education to allow consumers to make informed decisions about opting for generic medications.

\section{GENERIC DRUGS AND SUBSTITUTION: DEFINITION, STANDARDS, AND APPROACHES}

\section{A. Generic Drugs: What are They?}

Generic drugs are lower-cost drug alternatives that contain the same active ingredients as their brand name counterparts, but vary in terms of other characteristics, such as drug name, appearance (size, shape, color, etc.), and inactive ingredient makeup. ${ }^{22}$ Generic drugs are regulated by the FDA, and must fulfill several requirements as compared to brand name drugs to obtain approval: 1) they must contain the same active ingredients; 2) they must be identical in strength, dosage, form, and route of administration; 3) they must be manufactured according to FDA standards for branded drugs; 4) they must have the same intended use; 5) they must meet the same batch requirements for identity, strength, purity, and quality; and 6) they must be "bioequivalent." ${ }^{3}$ This Article is chiefly concerned with the last requirement.

Generic drugs must be "bioequivalent" to their brand name counterparts, meaning that they must show similar bioavailability, defined as "the rate of and extent to which the active ingredient or active moiety is absorbed from a drug product and becomes available at the site of action"

22 Depression \& Bipolar Support Alliance, Generic and Brand NAME DRUGS: Understanding The BASICS 4 (2007), available at http://www.dbsalliance.org/pdfs/GenericRx.pdf.

${ }^{23}$ What are Generic Drugs?, U.S. FoOD \& DRUG ADMIN., http://www.fda.gov/Drugs/ResourcesForYou/Consumers/BuyingUsin gMedicineSafely/UnderstandingGenericDrugs/ucm144456.htm, archived at http://perma.cc/59XM-GVFS (last updated May 12, 2009). 
under experimental conditions. ${ }^{24}$ The concept of bioequivalence is premised on the assumption that if two drugs have similar concentrations and absorption rates in terms of their shared active ingredient, they will be "similarly safe and effective." 25 A generic is considered to be bioequivalent when bioavailability ranges between 80\%$125 \%$ of the brand-name reference drug with $90 \%$ confidence, meaning there is a reasonable certainty that at least $90 \%$ of the time the average bioavailability of the generic drug will fall within that range. ${ }^{26}$ Further, bioequivalent drugs exist in two types: pharmaceutical equivalents and pharmaceutical alternatives. ${ }^{27}$

\section{B. State Approaches to Generic Substitution}

States consider six factors in formulating their generic substitution laws: 1) whether to require pharmacists to utilize the Orange Book (an FDA publication listing/providing guidelines for which generic medications are considered to be bioequivalent); 2) whether to mandate substitution; 3) whether to create a state drug formulary; 4)

24 Jesse C. Vivian, Generic Substitution Laws, 33 U.S. PHARMACIST 30 (2008), available at http://www.uspharmacist.com/content/s/44/c /9787/, archived at http://perma.cc/Q2K6-5EQP.

25 Pierre Blier \& Diane M. Sloan, $Q \& A$ : Generic Substitution for Psychotropic Drugs, 14 CNS SPECTRUMS 1, 4 (2009), available at http://www.cnsspectrums.com/UserDocs/0909CNS_Q_A_Blier.pdf, archived at http://perma.cc/7N3H-9N3P.

26 Jaime R. Hornecker, Generic Drugs: History, Approval Process, and Current Challenges, 34 U.S. Pharmacist 26, 26-30 (2009). In bioavailability trials, the FDA is concerned with three things compared to the branded drug: the generic's area under the curve (AUC), $\mathrm{C}_{\max }$, and $\mathrm{T}_{\max }$. AUC refers to the mean extent to which a drug's active ingredient is absorbed by the body. $\mathrm{C}_{\max }$ refers to the mean peak concentration that the active ingredient reaches in the body. $\mathrm{T}_{\max }$ refers to the mean time it takes for an active ingredient to reach its $\mathrm{C}_{\max }$. Scott Gavura, Generic Drugs: Are They Equivalent?, ScIEnce-BASED MEDICINE (Jan. 5, 2012), http://www.sciencebasedmedicine.org/genericdrugs-are-they-equivalent/, archived at http://perma.cc/2SVL-PG93.

27 Vivian, supra note 24. "Pharmaceutical equivalents" are generic drugs as they were defined supra Part II(A). "Pharmaceutical alternatives" are generic drugs that are "formulated with a different salt, ester, or complex." Id. 
whether to require consent from either the patient or a physician; 5) whether to require that a generic cost less than the brand name version; and 6) whether to recognize narrow therapeutic index (NTI) drugs. ${ }^{28}$

A majority of states require pharmacist use of the Orange Book to substitute, but a sizable minority make no reference to the Orange Book in their substitution laws. ${ }^{29}$ Concerning mandated substitution, the prevailing approach is for states to permissively allow for substitution at the pharmacist's discretion or in accordance with other regulations, though a minority mandate substitution when a suitable generic is available. ${ }^{30}$ Regarding consent, the

28 Id. According to the FDA, NTI drugs are those "containing certain drug substances that are subject to therapeutic drug concentration and pharmacodynamic monitoring," U.S. DEPT. OF Health and Human Serv. Food and Drug Admin. Ctr. For Drug EVALUATION AND RESEARCH, GUIDANCE FOR INDUSTRY: WAIVER OF IN Vivo BIOAVAILABILITY AND BIOEQUIVALENCE STUdiES For IMMEDiaTeRELEASE SOLID ORAL DOSAGE Forms BASED ON A BIOPHARMACEUTICS ClASSIFICATION SYSTEM 9 (2000). NTI drugs are dangerous because the ranges at which these drugs produce therapeutic and toxic effects are close together, making it easy to cross one threshold into another. Liang et al., Illegal "No Prescription" Internet Access to Narrow Therapeutic Index Drugs, 35 CliniCAL Therapeutics 694, 694 (2013).

${ }^{29}$ Vivian, supra note 24.

30 See id.; Avalere Health, LLC., State Policies Regarding GENERIC Substitution, 20102 (2010); U.S. DeP’T OF HEALTH \& Human Serv., ASPE Issue Brief: Expanding The Use Of Generic Drugs APPENDIX A (2010). Nearly all states allow for physicians to preemptively override substitution by marking prescriptions to be filled with the branded medication only. See Avalere Health, LLC, supra, at 3; U.S. DeP'T of Health \& Human SERV., supra, at Appendix A. However, given the decreasing amount of time that doctors are spending with their patients, sometimes as little as eight minutes for newer doctors, it is unclear how often doctors and patients discuss preferences for brand name medications. See Pauline W. Chen, For New Doctors, 8 Minutes Per Patient, N.Y. Times Well Blog (May 30, 2013, 12:01 AM), http://well.blogs.nytimes.com/2013/05/30/for-new-doctors-8-minutes-perpatient/?_php=true\&_type=blogs\&_r=0, archived at http://perma.cc/8YQL-5W87; Danielle Ofri, The Doctor Will See Your Electronic Medical Record Now, Slate Future Tense Blog (Aug. 5, 2013 , $12: 27$ PM), http://www.slate.com/blogs/future_tense/2013/08/05/study_reveals_docto rs_are_spending_even_less_time_with_patients.html, archived at http://perma.cc/YXH4-HGES. 
predominant approach among states is to require patient or physician notification, but a handful require no notification. ${ }^{31}$ Considering the creation of drug formularies, the majority of states have not established them; those that have established formularies did so either by generating a list of drugs that are considered to be interchangeable (positive formulary) or by establishing a list of drugs that are not suitable for substitution (negative formulary). 32 Additionally, a majority of states employ a cost savings requirement, and only a small minority recognize NTI drugs. ${ }^{33}$

\section{ScIENTIFIC Issues With GeneRIC Substitution}

Though many states favor generics because they cost less than their brand name counterparts and are theoretically equally effective, generic drugs remain controversial due to concerns over the way in which bioequivalence testing is carried out and concerns because generics have differing inactive ingredients from the brand name drug, which can impact drug performance. This section will explore these two drawbacks in detail.

\section{A. The Limits of Pharmacokinetic Studies}

The bioequivalence of generic drugs is typically tested via pharmacokinetic studies in which the test generic and branded reference drugs are compared in terms of how

31 See Vivian, supra note 24; AVALERE HEALTH, LLC., supra note 30, at 4; U.S. DEP'T OF HEALTH \& HUMAN SERV., supra note 30, at Appendix A. As of 2008 , four states allowed for mandatory substitution without consent being required: Massachusetts, New Jersey, Rhode Island, and Washington. Seven other states allow for substitution without consent: Alabama, Arkansas, Louisiana, New Mexico, North Carolina, Oregon, and Tennessee. Vivian, supra note 24. A handful of states approach Medicaid patients differently, requiring no patient consent and mandatory substitution: Massachusetts, New Jersey, New Mexico, Oregon, Rhode Island, Tennessee, Washington, and Wyoming. William H. Shrank et al., State Generic Substitution Laws Can Lower Drug Outlays Under Medicaid, 29 HeAlth AFFaIRs 1383, 1386 (2010).

32 Vivian, supra note 24.

${ }_{33} I d$. 
quickly the active ingredient in the drugs reaches the absorption site and how much of the active ingredient is absorbed. ${ }^{34}$ These studies are based on a single-dose administration of the two drugs in a sample of 24 to 36 volunteers. ${ }^{35}$ However, there are several problems with these pharmacokinetic studies. First, bioequivalence studies typically involve sample groups of healthy adult male volunteers who take no other medications, do not smoke, receive a controlled diet, are of average height and weight, and are between 18 and 55 years old. ${ }^{36}$ As such, these samples necessarily exclude any investigation of the impact of individual differences in patients that might influence the performance of a medication. ${ }^{37}$ This is undesirable because it violates a basic premise of statistics: to extrapolate findings to a population, a sample needs to be representative of that population. A sample such as the one described likely is not representative of all the patient populations to which the results of the pharmacokinetic study will be extrapolated, least of all the patient population with the actual illness or disorder that the drug is designed to treat. 38

Second, the use of a single regulatory acceptance range may be problematic for NTI drugs, or "drugs for which a relatively small change in systemic concentration can lead to marked changes in pharmacodynamics response." 39 In fact, a bioavailability difference as small as 3.5\% may yield clinical consequences. ${ }^{40}$ Using anticonvulsants as an example, this small difference could result in seizures at the

$34 \mathrm{Id}$.

35 Id.

36 Peter Meredith, Commentary: Bioequivalence and Other Unresolved Issues in Generic Drug Substitution, 25 CLINICAL THERAPEUTICS 2875, 2878-79 (2003).

37 Id.

38 Id. at 2879.

39 Id. Carbamazepine is an anticonvulsant whose extended-release versions are commonly prescribed to treat bipolar disorders. See Carbamazepine, U.S. NAT'L INST. OF HEALTH, http://www.nlm.nih.gov/medlineplus/druginfo/meds/a682237.html, archived at http://perma.cc/MHV4-ERZS (last updated Mar. 2, 2015).

40 Barbara J. Zarowitz \& Todd Semla, Avoiding Potential Pitfalls of Generic Substitution, 30 GERIATRIC NuRSING 260, 261 (2009). 
low end or toxicity at the higher end of the bioavailability spectrum. ${ }^{41}$ Third, as bioequivalence is predicated on the assumption that similar bioavailability yields similar treatment results, ${ }^{42}$ a generic drug does not require a "demonstration of its pharmacokinetics, efficacy, and tolerability in normal and healthy subjects and in the target patient population," as branded drugs are required to do. ${ }^{43}$ This undermines the fundamental assumption of bioequivalence, as it is not an established fact that two drugs with similar bioavailability demonstrate equivalent clinical efficacy, only that they demonstrate similar rates and extent of absorption of their active ingredient. ${ }^{4}$

Fourth, bioequivalence studies involve the administration of a single dose of the generic test and branded reference drugs, yet results of these studies are extrapolated to predict the results of use of multiple doses of the drug. ${ }^{45}$ Like the example of the homogenous, nonrepresentative sample described above, this procedure raises generalizability concerns. In actual use, few drugs are administered in single doses; instead, most drugs require maintenance of a steady regimen to achieve the desired therapeutic result. 46 The level of drug present in a patient following maintenance of a steady medication regimen is usually substantially higher than the drug levels present with just a single-dose administration, making bioequivalence studies that do not account for this regimen especially problematic. ${ }^{47}$ Also, evidence indicates that the differing inactive ingredients present in generic drugs may influence the metabolism, absorption, and distribution of a drug's active ingredient when on a steady maintenance regimen in ways that are not observable following a singledose administration. ${ }^{48}$ Lastly, an experiment consisting of a single-dose administration may not properly capture the

\footnotetext{
${ }^{41} \mathrm{Id}$.

42 Blier \& Sloan, supra note 25.

${ }^{43}$ Meredith, supra note 36, at 2878.

${ }^{44} I d$.

$45 I d$. at 2879 .

${ }^{46} \mathrm{Id}$.

${ }^{47} \mathrm{Id}$.

${ }_{48} I d$.
} 
effects of drugs that have variable pharmacokinetic profiles the way that a multi-dose experiment might. 49

\section{B. Bioequivalence: Do Generic Drugs Really Produce the Same Effects as Brand Names?}

Although generic drugs are theoretically thought to produce the same results as their brand name counterparts, in reality this may not be true. Though generic and brand name drugs share active ingredients, they may differ in terms of their inactive ingredients or the salt form in which the active ingredient is presented.50 These inactive ingredients and differing salt forms can impact the performance of generic drugs in a number of ways.

Inactive ingredients can influence the effects of a generic drug in two ways. First, and perhaps most obviously, some individuals may be allergic to the inactive ingredients in generic drug formulations, rendering the generic intolerable. 51 Second, generic and brand name drugs may contain different excipients, or inert substances included in a drug to assist in the process of drug manufacturing, administration, and active ingredient absorption. ${ }^{52}$ These excipients may trigger, promote, or partake in chemical or physical interactions with a drug's active ingredient that can jeopardize drug performance and quality. ${ }^{53}$ Chemical interactions between active ingredients and excipients may result in drug intolerability, diminished drug safety, and

49 Id. at 2880 .

50 Meredith, supra note 36, at 2880. A drug's salt form refers to an "ionisable drug that has been combined with a counter-ion to form a neutral complex." Producing a drug in salt form makes it more chemically stable, allows its pharmacokinetic profile to be manipulated, and allows for easy administration. Aateka Patel et al., Pharmaceutical Salts: A Formulation Trick of a Clinical Conundrum? 16 BRIT. J. CARDIOLOGY 281, 281 (2009).

51 Tod Cooperman, What You Need to Know About Generic Drugs, DR. Oz SHOw (Apr. 8, 2013), http://www.doctoroz.com/videos/what-youneed-know-about-generic-drugs.

${ }^{52}$ Patrick Krowley \& Luigi G. Martini, Drug-Excipient Interactions, Pharmaceutical Tech. Eur. 26 (Mar. 2001) available at http://callumconsultancy.com/articles/DrugExcipientInteractions.pdf.

${ }^{53} I d$. 
degradation of a drug's active ingredient. ${ }^{4}$ Physical interactions may impact a drug's dissolution, its dosage uniformity, or its ease of administration..$^{55}$

Turning next to differing salt forms, the type of salt used to formulate a drug is important, particularly for psychotropic drugs, in that it can influence a drug's physicochemical properties, such as stability, fluidity, and ability to absorb moisture, as well as a drug's kinetics and active ingredient absorption rate. ${ }^{56}$ As previously mentioned, drugs containing different salts of the same active substance are called pharmaceutical alternatives ${ }^{57}$ and are popular among generic drug makers because they allow for a route around a patent, facilitating earlier entry into the market.58 However, although pharmaceutical alternatives allow for consumers to gain quicker access to generic drug formulations, there are several potential detriments.

First, the salt form of a drug's active ingredient impacts its aqueous solubility, which can lead to disparate in vivo dissolution characteristics between generics and brand names.59 This is important because the dissolution characteristics of a drug determine its active ingredient's extent and rate of absorption. ${ }^{60}$ Second, differential salt forms of an active ingredient can generate toxicity concerns due to the different conjugate anions or cations used to form the salt compound as well as chemical impurities that may arise during salt formulation. ${ }^{61}$ Third, an active ingredient's salt form may influence its tolerability, causing undesirable side effects such as stomach irritation or

\footnotetext{
${ }^{54} I d$.

${ }_{55} \mathrm{Id}$.

56 Pawel Lewek \& Przemyslaw Kardas, Generic Drugs: The Benefits and Risks of Making the $S_{w i t c h,} 59$ J. FAM. PRAC. 634, 638 (2010).

${ }^{57}$ Vivian, supra note 24.

${ }^{58}$ R. K. Verbeeck et al., Generic Substitution: The Use of Medicinal Products Containing Different Salts and Implications for Safety and Efficacy, 28 EUR. J. Of PHARMACEUTICAL SCI. 1, 1 (2006).

${ }^{59} \mathrm{Id}$. at 3.

${ }^{60} \mathrm{Id}$.

${ }^{61} I d$. at $3-4$.
} 
stomach ulcers. ${ }^{62}$ Fourth, salt forms impact polymorphism, or "the ability of a drug substance to exist as two or more crystalline phases that have different arrangements and/or conformations of the molecules in the crystal lattice."63 Polymorphism is important because it impacts equilibrium solubility, a factor in determining the dissolution rate of an active ingredient that can influence bioavailability after oral administration of a medication. ${ }^{64}$ Last, the salt form of an active ingredient can influence its physiochemical properties, which affect a drug's formulation as well as its large-scale manufacturing by potentially negatively impacting the uniformity, disintegration, and dissolution rate of solid medications. ${ }^{65}$

Two other concerns with generic drug formulations are a drug's water solubility for NTI drugs and the pharmacokinetic profile of modified-release formulations. ${ }^{66}$ Regarding the former, water solubility in NTI drugs could lead to concentration differences that can diminish a drug's effectiveness or render it toxic. ${ }^{67}$ Concerning the latter, active ingredient concentration profiles in modified-release formulations may differ between generics and brand names during the absorption period of an active ingredient, which might impact a drug's effectiveness despite the fact that the generic drug may technically meet bioequivalence standards. ${ }^{6}$

\section{Generic Substitution AND Mental ILlness}

Psychotropic medications are drugs targeted at treating and managing the symptoms of mental health disorders. ${ }^{69}$ They work by adjusting chemical levels in the brain that

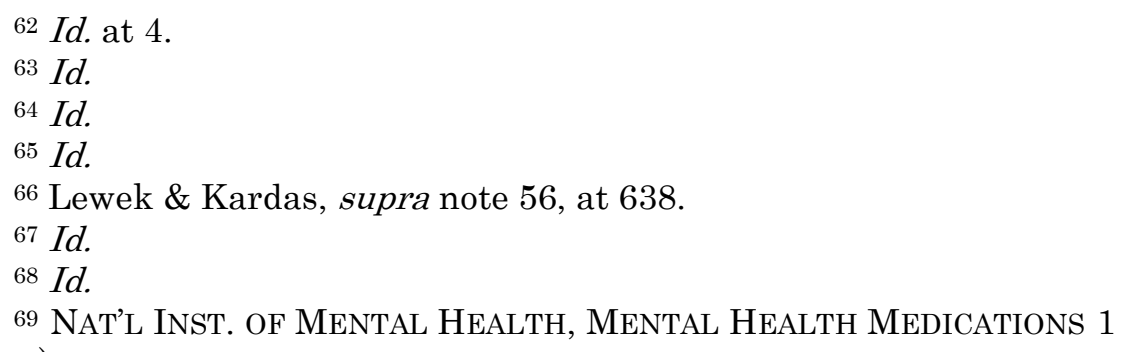


influence behavior and mood. ${ }^{70}$ Psychotropic medications are used to treat a variety of mental health disorders such as bipolar disorders, anxiety disorders, depressive disorders, and psychotic disorders. ${ }^{71}$ Unfortunately, psychotropic medications are not a cure for mental illness; however, they can be effective in allowing individuals to better function in everyday life. ${ }^{72}$ This section will provide background on the four major classes of mental health disorders that psychotropic drugs treat, examine the effectiveness of generic psychotropics in treating these disorders, discuss the potential benefits and detriments that consumers may experience if they use generic psychotropics, and outline reasons why we should care about the potential differential effectiveness of these drugs.

\section{A. How Effective are Generics at Treating Mental Illness?}

\section{Bipolar Disorders}

Bipolar disorders are mood disorders characterized by the tendency of an individual to vacillate between moods, with the most notable moods being manic (or hypomanic) episodes and major depressive episodes. ${ }^{73}$ Manic episodes are characterized by an extended period of excessive elation or euphoria, often in combination with hyperactivity, decreased need for sleep, and grandiosity; major depressive episodes are characterized by an extended period of severe depression in conjunction with sleep disturbances, decreased interest in and experience of pleasure of

70 Enjoli Francis, Psychotropic Drugs: What are They?, ABC News HEALTH BLOG (Dec. 2, 2011, 5:04 PM), http://abcnews.go.com/blogs/health/2011/12/02/what-you-need-to-knowabout-psychotropic-drugs/, archived at http://perma.cc/4HDB-LZA6.

${ }^{71}$ NAT'L Inst. Of MENTAL HEALTH, supra note 69, at 1.

$72 I d$.

73 Am. Psychiatric Ass'N, Diagnostic and Statistical Manual of MENTAL DisORDERS: DSM-5 123 (5th ed. 2013). Bipolar disorder presents in two forms: 1) bipolar I, characterized by the experience of at least one manic episode, and 2) bipolar II, characterized by at least one major depressive episode and one hypomanic episode. Id. at 123-27, 13235 . Hypomanic episodes are periods of elevated mood that fall between normal mood and manic episodes. Id. at 124 . 
previously interesting or pleasurable activities, and feelings of worthlessness. ${ }^{74}$ Bipolar disorders are chronic, often manifesting themselves in adolescence or early adulthood and lasting throughout an individual's lifetime. ${ }^{75}$ Prevalence rates for bipolar disorders are low, with about $.6 \%$ of the United States population experiencing bipolar I annually and .8\% experiencing bipolar II annually. ${ }^{76}$ Like some other mood disorders, bipolar is strongly associated with suicide, with some estimates showing that about onethird of individuals with bipolar I or II attempt suicide at some point during their lifetime. ${ }^{77}$ This places bipolar individuals at a suicide risk that is at least fifteen times as great as that of individuals without bipolar; further, bipolar individuals may account for up to $25 \%$ of suicides. ${ }^{78}$

Most clinicians regard medication to be a necessary component in treating bipolar disorder. ${ }^{79}$ Historically, the most common medications for bipolar disorders were moodstabilizing drugs containing lithium carbonate. ${ }^{80}$ Research has long shown lithium to be a successful treatment for mania, ${ }^{81}$ being effective in about $50 \%$ of patients and providing approximately a 50\% reduction in manic symptoms. ${ }^{82}$ However, despite initial treatment success,

${ }^{74} \mathrm{Id}$. at 123.

$75 \mathrm{Id}$.

76 Id. at $130,136$.

$77 \mathrm{Id}$. at 138 .

$78 \mathrm{Id}$. at 131.

79 NAT'L Alliance On MENTAL Illness, Bipolar Disorder 7 (2011).

80 Michael E. Thase \& Timothey Denko, Pharmacotherapy of Mood Disorders, 64 ANN. REV. CliniCAL Psychol. 53, 72 (2008). Mood stabilizing drugs are drugs that are generally considered to produce antimanic effects while either not worsening or alleviating depressive symptoms; however, some have proposed a more tailored definition, suggesting that mood stabilizers are those drugs that both alleviate acute manic and depressive symptoms as well as prevent manic and depressive symptoms. See Mark S. Bauer \& Landis Mitchner, What is a "Mood Stabilizer"? An Evidence-Based Response, 161 AM. J. PsYCHIATRY 3 , 3 (2004).

81 Frederick K. Goodman \& S. Nassir Ghaemi, Understanding Manic-Depressive Illness, 55 Archives GEN. Psychol. 23, 24 (1998).

82 Paul E. Keck, Jr. \& Husseini K. Manji, Current and Emerging Treatments for Acute Mania and Long-Term Prophylaxis for Bipolar 
relapse rates for individuals on lithium are high, with upwards of $70 \%$ of individuals experiencing a relapse within two to five years of commencing the medication. ${ }^{83}$ Further, lithium has serious side effects, as improper dosages can result in poisoning, impaired functioning of the thyroid, significant weight gain, and the development of diabetes insipidus. ${ }^{84}$ Less serious side effects of lithium include sedation, nausea, appetite loss, diarrhea, dizziness, hand tremors, increased thirst, and increased urination. ${ }^{85}$ These side effects, coupled with the nature of bipolar in general (some individuals enjoy the upswing in mood that occurs during hypomanic episodes or the euphoria associated with mania), often encourage poor medication compliance, significantly increasing individuals' chances for relapse. 86

For those individuals who do not respond to lithium, anticonvulsant drugs, such as those used to treat epilepsy, may help to address manic symptoms; in fact, anticonvulsants-specifically, valproate-have recently overtaken lithium-based medications as the most commonly prescribed medications to treat bipolar disorders. ${ }^{87}$ Anticonvulsants have evidenced similar effectiveness as compared to lithium in managing the symptoms of bipolar; however, while similarly effective at managing bipolar symptoms, anticonvulsants are substantially less effective than lithium at preventing suicide. ${ }^{88}$ In fact, the rate of

Disorder, in Neuropsychopharmacology: The FifTh GENERATION OF Progress 1109, 1109 (Kenneth L. Davis et al. eds., 2002).

${ }^{83}$ Martha Sajatovic, Bipolar Disorder: Disease Burden, 11 AM. J. MANAGED CARE S80-4 3 Supp. (2005), available at http://www.ajmc.com /publications/supplement/2005/2005-06-vol11-n3Suppl/Jun05-2075pS80S84/.

84 Medications, NAT'L AlliAnCE ON MENTAL ILlness, http://www.nami.org/Template.cfm?Section=About_Medications\&Templ ate $=/$ TaggedPage/TaggedPageDisplay. cfm $\&$ TPLID $=51 \&$ ContentID $=208$

20, archived at http://perma.cc/ENC4-EMEP (last visited Mar. 18, 2015).

${ }^{85} \mathrm{Id}$.

${ }^{86}$ Key Points About Treatments for Bipolar Disorder, BLACK DoG INST., http://www.blackdoginstitute.org.au/public/bipolardisorder/treatments/bipo lardisorder.cfm, archived at http://perma.cc/V49C-VNGQ (last visited Mar. 18, 2015).

87 Thase \& Denko, supra note 80, at 72.

$88 \mathrm{Id}$. 
completed suicides while taking anticonvulsants is nearly three times as great as the rate for individuals taking lithium. 89

Though studies examining the effectiveness of generic lithium to branded drugs are extremely scarce, a handful of studies examining the effectiveness of generic versus branded anticonvulsants in the treatment of bipolar disorders exists due to the significant amount of literature on generic versus branded drugs in the treatment of epilepsy that includes bipolar outcomes; a handful of studies have also examined the comparative effectiveness of other antidepressants and mood stabilizers. Results from a 1979 study found sub-therapeutic levels of lithium in the blood for generic as opposed to branded lithium-based mood stabilizers. ${ }^{90}$ Regarding anticonvulsants, one study indicates that depressive symptoms and suicidal thoughts worsened upon switching from branded divalproex to generic valproic acid (though this occurred in a patient with schizophrenia), and several studies suggest an increase in gastrointestinal side effects when taking generic versus branded valproic acid.91 Several studies have indicated potential deleterious side effects for generic as opposed to branded lamotrigine, with one study observing increases in anxiety, mood swings, dizziness, agitation, headaches, insomnia, and bad taste in the mouth, and another study observing side effects of ataxia, falls, and vertigo. ${ }^{92}$

\section{Anxiety Disorders}

Anxiety disorders are characterized by persistent feelings of anxiety, apprehension, and tension, usually centered around perceived future misfortune or danger. ${ }^{93}$ These feelings may manifest themselves emotionally

89 Id.

90 Julie E. Desmarais et al., Switching from Brand-Name to Generic Psychotropic Medications: A Literature Review, 17 CNS NEUROSCIENCE \& THERAPEUTICS 750, 751 (2011).

91 Id. at $751-53$.

92 Id. at 753-54. Antidepressants and other mood stabilizers are discussed infra Section $\operatorname{III}(\mathrm{A})(3)$.

93 AM. PsychiatriC AsS'N, supra note 73, at 189. 
(fear/phobias, reliving trauma), physiologically (fight-orflight arousal, muscle tension and panic attacks), behaviorally (facial expressions, fidgeting, avoiding stimuli associated with trauma, repetitive or impulsive behaviors), and cognitively (obsessions/compulsions).94 Anxiety disorders are common, with Generalized Anxiety Disorder (GAD) estimated to impact .9\% of American children, 2.9\% of adults annually, and 9\% of people within their lifetime; 95 Panic Disorder (PD) affecting 3\% of the population annually;96 and Posttraumatic Stress Disorder (PTSD) affecting $8.7 \%$ of the population by age 75 and $3.5 \%$ annually. ${ }^{97}$ However, social phobia and specific phobias are more prevalent, affecting an estimated $7-9 \%$ of the population every year, though the annual rate of specific phobias is roughly doubled in adolescents.98 Obsessivecompulsive disorder (OCD) is more rare by comparison, with prevalence rates of $1.2 \%$ annually. ${ }^{99}$

Medication is commonly used to treat anxiety disorders, with several classes of medications demonstrating efficacy. Benzodiazepines may be used to treat GAD and PD;100 however, benzodiazepines are not recommended for longterm use given that they do not alleviate symptoms for onethird of people, may impair cognition, exhibit potential for abuse and withdrawal, and, in some studies, show no therapeutic benefit past four to six weeks. ${ }^{101}$ Regarding PD,

94 Id. at 235.

95 Id. at 223.

96 Id. at 210.

97 Id. at 276. In the DSM-5, PTSD is no longer categorized with the Anxiety Disorders as in the DSM-IV-TR, but rather with Trauma- and Stressor-Related Disorders. AM. PsYCHIATRIC Ass'N , Highlights OF CHANGES FROM DSM-IV-TR TO DSM-5 5 (2013), available at http://www.dsm5.org/Documents/changes\%20from\%20dsm-iv-

tr\%20to\%20dsm-5.pdf.

98 AM. PSYCHIATRIC Ass'N., supra note 73, at 204.

$99 \mathrm{Id}$. at 239. In the DSM-5, OCD is no longer categorized with the Anxiety Disorders as in the DSM-IV-TR, but rather is given its own classification. AM. PSYCHIATRIC ASS'N., supra note 97, at 5.

100 Joseph Rabatin \& Lynn Buckvar Keltz, Generalized Anxiety and Panic Disorder, 176 W. J. MED. 164, 165-67 (2002).

101 Jack M. Gorman, Treating Generalized Anxiety Disorder, 64 J. CliniCAL PsYchiatry 24, 25 (2 Supp. 2003); but see generally Vladan 
though benzodiazepines have shown therapeutic success, the relapse rate when they are discontinued is quite high, hovering close to $90 \% .{ }^{102}$

Two types of antidepressants, selective serotonin reuptake inhibitors (SSRIs) and serotonin norepinephrine reuptake inhibitors (SNRIs), have shown efficacy for PD;103 however, SSRIs may cause sexual dysfunction, a side effect that can discourage treatment compliance. ${ }^{104}$ This is a concern, especially given that the general medication compliance rate is only about $20 \%$ across medications. ${ }^{105}$ Concerning OCD, SSRIs benefit approximately $60 \%$ of patients, though relapse is common if use of the medication is discontinued. ${ }^{106}$ Additionally, multiple classes of antidepressants may help to relieve symptoms of social anxiety, 107 and SSRIs may help to relieve symptoms of PTSD. 108

Although not as extensive as the literature comparing generics and branded drugs for other mental health disorders (though, realistically the literature is thin for all

Starcevic, The Reappraisal of Benzodiazepines in the Treatment of Anxiety and Related Disorders, 14 EXPERT REV. NEUROTHERAPEUTICS 1275 (2014) (arguing that recent research suggests that benzodiazepines are safe for long-term use and should be considered a first-line, long-term treatment for GAD and PD).

102 Abby J. Fyer et al., Discontinuation of Alprazolam Treatment in Panic Patients, 144 AM. J. PsychiATRY 303 (1987), available at http://www.benzo.org.uk/alprazolam.htm, archived at http://perma.cc/SNL7-7D3A.

103 Charles B. Pull \& Cristian Damsa, Pharmacotherapy of Panic Disorder, 4 NeURopyschiatRic Disease \& TREATMEnT 779, 781-785 (2008).

104 Deepak Prabhakar \& Richard Balon, How Do SSRIS Cause Sexual Dysfunction?: Understanding Key Mechanisms can Help Improve Patient Prognosis, Adherence, 9 CURRENT PSYCHIATRY 30, 30 (2010).

105 V. MARK DURAND \& DAVID H. BARLOW, EsSENTIALS OF ABNORMAL PSYCHOLOGY: InSTRUCTOR's EDITION 132-33 (6th ed. 2013).

106 Id. at 155 .

107 Michael Van Ameringen et al., Pharmacotherapy for Social Anxiety Disorder: An Update, 46 IsRAeli J. Psychiatry \& RELATED SCI. 53, 53 (2009).

108 Gregory M. Asnis et al., SSRIS Versus Non-SSRIS in PostTraumatic Stress Disorder: An Update with Recommendations, 64 DRUGS 383, 383-91 (2004). 
mental illnesses), a couple case studies exist comparing generic anti-anxiety medications to their brand name counterparts. A 1997 study suggested that generic clonazepam may cause greater levels of sedation and decreased management of anxiety compared to the branded version; additionally, generic clonazepam was associated with side effects of fatigue and dizziness. 109 A 1991 case study indicated that a middle-aged woman with severe PD experienced panic attacks when switched from her original generic to generic alprazolam; these attacks were not present with the original generic and disappeared when the original generic was reinstituted. 110

\section{Major Depressive Disorder}

Major Depressive Disorder ("MDD") is characterized by recurrent depressed mood (including the presence of a major depressive episode), cognitive distortions, and impaired physical functioning to the point where it causes significant distress and impairment and interferes with daily functioning. 111 Common symptoms include feelings of worthlessness, guilt, or indecisiveness; loss of energy; fatigue; diminished interest in once enjoyable activities; psychomotor disturbances; difficulties in thinking and concentrating; significant weight fluctuations; sleep disturbances; and suicidal ideation. ${ }^{112}$ MDD is quite prevalent, with $16.2 \%$ of individuals estimated to experience the disorder at some point in their lifetime and 6.6\% experiencing the disorder within any given year; these percentages may be significantly higher in elderly individuals and in women.113 Disconcertingly, MDD is associated with a high risk of suicide, with untreated individuals having a lifetime risk of about $20 \%$, and the rate

${ }^{109}$ Desmarais et al., supra note 90, at 756 .

110 Id. at 757.

111 AM. PSYCHIATRIC Ass'N, supra note 73, at 160.

112 Id. at $160-63$.

${ }^{113}$ Derek Richards, Prevalence and Clinical Course of Depression: A Review, 31 CLINICAL PSYCHOL. REV. 1117, 1118 (2011). 
of completed suicides being twenty times higher than that of the general population. ${ }^{114}$

MDD is often treated with antidepressant medications, which fall into one of four categories: SSRIs, monoamine oxidase inhibitors ("MAOI"), mixed reuptake inhibitors, and tricyclic antidepressants. ${ }^{115}$ Research indicates that all four types of antidepressants, at least initially, are equally efficacious, reducing depressive symptoms in about 50\% of patients and achieving remission of depressive symptoms in about $25 \%$ of patients. ${ }^{116}$ However, the drugs differ in terms of their side effects: SSRIs may produce physical agitation, sexual dysfunction, decreased sex drive, insomnia, and upset stomach; MAOIs, in combination with the consumption of foods and drinks containing tyramine, may cause hypertension or even death; and tricyclic antidepressants may produce vision difficulties, difficulties in waste elimination, dry mouth, drowsiness, sexual dysfunction, and weight gain; all of these side effects may lead to reduced levels of medication adherence. ${ }^{117}$ Further, despite medication use, relapse rates for depression are high, with $50 \%$ of patients relapsing if medication use is discontinued too soon after a major depressive episode. ${ }^{118}$

Though branded antidepressants appear to be effective in the treatment of some depressive disorders, generic versions may not perform as well by comparison, as indicated by a handful of studies. ${ }^{119}$ Generic amitriptyline

114 Am. Ass'n of Suicidology, Some Facts About Suicide and Depression, AM. Ass'N. OF SuICIDOlOGY, 1, 2 (2010), http://211bigbend.net/PDFs/factsaboutsuicideanddepression.pdf.

115 Mayo Clinic Staff, Antidepressants: Selecting the One That's Right for You, MAYO ClinIC, (Nov. 18, 2014), http://www.mayoclinic.org/diseases-conditions/depression/indepth/antidepressants/art-20046273, archived at http://perma.cc/684A2BHW (also noting that another type of antidepressant, the "atypical" antidepressant, is grouped in a catch-all category because it does not fall neatly into any particular category of antidepressants).

116 DURAND \& BARLOW, supra note 105, at 227.

117 Id. at $227-28$.

118 Id. at 233.

119 Christoph U. Correll \& Maren Carbon, Branded vs. Generic Psychotropic Medication: Is One Better than the Other?, NWPMD 1 (2012), 
produced worsened depression symptoms, decreased blood levels, and increased agitation compared to the branded version; generic mirtazapine (Avanza), desipramine (Norpramin), paroxetine (Paxil), citalopram (Celexa), and fluoxetine (Prozac) are also reported to produce worsened depressive/psychiatric symptoms compared to branded versions. 120 Generic fluoxetine was reported to produce increased anxiety, allergic reactions, relapse of comorbid obsessive-compulsive disorder, and diarrhea; additionally, generic nortiptyline (Aventyl) was reported to produce severe intoxication. ${ }^{121}$ Finally, at least one study of generic venlafaxine (Efexor) indicates that its bioavailability does not fall within the acceptable $80 \%$ to $125 \%$ range of its branded reference drug as required by the FDA. ${ }^{122}$

\section{Schizophrenia and Psychotic Disorders}

Schizophrenia is a psychotic disorder characterized by a mixture of cognitive, emotional, perceptual, speech, and behavioral disturbances. Common symptoms include disorganized speech, displaying inappropriate emotions or flat affect, experiencing hallucinations and/or delusions, paranoia, and catatonic movement. ${ }^{123}$ Schizophrenia affects about .7\% of people at some point in their lives, and the disorder can produce numerous deleterious effects for the individuals who suffer from it, as well as cast a significant financial burden on society; it is estimated that the cost of treating schizophrenics may exceed $\$ 60$ billion annually. ${ }^{124}$ Schizophrenia is a chronic disorder. Even with treatment, full and complete recovery is rare; however, psychotic symptoms tend to subside over time. ${ }^{125}$ As such, the treatment focus for those with schizophrenia is often not on curing the disorder but on managing its symptoms. This is

https://www.nwpmd.com/Portals/0/Gallery/Articles/Branded\%20vs\%20G eneric\%20Psychotropic\%20Medications\%20(printer-friendly).pdf.

$120 \mathrm{Id}$.

121 Id.

${ }^{122} I d$.

123 AM. PSYCHIATRIC Ass'N, supra note 73, at 100-01.

${ }^{124} \mathrm{Id}$. at 102.

${ }^{125} \mathrm{Id}$. at $102-03$. 
commonly carried out through the administration of antipsychotic medications. ${ }^{126}$

Research regarding medications for schizophrenia reveals some troubling findings. First, although antipsychotics can help to alleviate symptoms of schizophrenia, they only do so in about $60 \%$ of individuals. $^{127}$ Second, medication adherence rates for those with schizophrenia are low, with some studies finding that nearly three-quarters of those with schizophrenia stop taking their medications within eighteen months. ${ }^{128}$ Third, antipsychotics can produce a host of uncomfortable side effects, such as grogginess, blurred vision, dry mouth, akinesia, and motor abnormalities, which contribute to the aforementioned low medication adherence rate. ${ }^{129}$

Though the treatment of schizophrenic individuals with branded medications already presents some difficulties, these difficulties can be compounded when generic medications are utilized. Although some studies suggest generic and branded first-generation antipsychotics perform equivalently, other studies suggest that patients on generic versions may require increased dosage adjustments and may experience exacerbated side effects, such as unprovoked outbursts and drowsiness. ${ }^{130}$ Similarly, although a handful of studies have demonstrated the efficacy of generic clozapine in treating schizophrenia, another handful have suggested that individuals receiving generic clozapine experience either worsened symptoms or relapse at greater rates than do individuals on branded versions. 131 Regarding another antipsychotic, risperidone,

126 Kiran Panesar, Schizophrenia: Managing Symptoms with Antipsychotics, 37 U.S. PHARMACIST (EPUB.) (Nov. 20, 2012), http://www.uspharmacist.com/content/d/web_exclusive/c/37743/.

127 DURAND \& BARLOW, supra note 105, at 472-73.

128 Id.

129 CONSUMER Reports Best Buy Drugs, Evaluating PREscription Drugs Used To TREAT SCHIZOPHRENIA AND BipolaR Disorder: CoMPARING EFFECTIVEnESS, SAFETy, AND PRICE 8 (2009), available at http://www.consumerreports.org/health/resources/pdf/bestbuy-drugs/AntipsychoticsFINAL.pdf.

${ }^{130}$ Desmarais et al., supra note 90 , at 755 .

$131 \mathrm{Id}$. 
at least one study challenged the bioequivalence of generic versions of the drug to the branded Risperdal ${ }^{\circledR}, 132$ indicating that the generic's bioavailability did not fall within the FDA's required $80 \%$ to $125 \%$ range. ${ }^{133}$

\section{B. Benefits and Detriments of Generic Substitution of Medications for Consumers}

The substitution of generic versions of psychotropic medications provides at least one potential benefit to consumers. Although inactive ingredients in generic medications may influence the way that drugs are absorbed into the body, this risk is more severe for drugs with narrow therapeutic indexes; the risks of differential effectiveness of generic in comparison to branded drugs is less pronounced for psychotropic drugs with high therapeutic indexes. ${ }^{134}$ To this end, the cost savings provided by using generic psychotropics may be well worth the small risk of differential effectiveness between generics and brand names for drugs with high therapeutic indexes. For some drugs, the costs savings can be substantial; for example, the branded amphetamine Adderall ${ }^{\circledR 135}$ costs approximately $\$ 84$ for a 30-day supply, whereas generics Dexedrine ${ }^{\circledR}$ and dexamphetamine cost over $\$ 50$ less for the same thirty-day supply. ${ }^{136}$ Similarly, a $60 \%$ increase in the dispensing of generic antidepressants decreased medication costs by 9\%. ${ }^{137}$ Additionally, this reduction in price may also indirectly impact treatment compliance; lower copays may increase the likelihood that consumers are willing to persist in therapy. ${ }^{138}$

132 RISPERDAL, Registration No. 1830761.

133 Desmarais et al., supra note 90, at 755 .

134 Laura LaDue, Generic Psychotropic Medications: Issues of CostEffectiveness and Patient Benefit, 104 S. MED. J. 711, 712 (2011). See also Liang et al., supra note 28 , for a refresher regarding the dangers of NTI drugs.

135 ADDERALL, Registration No. 1908092.

${ }^{136}$ LaDue, supra note 134, at 712.

137 Id.

138 Lewek \& Kardas, supra note 56, at 638. 
Despite the economic benefit for consumers stemming from the substitution of generic drugs for branded versions, consumers may also experience myriad detriments. First, as discussed above, generic psychotropics, at least for some individuals, may not be as effective at treating their mental illness as brand name psychotropics. ${ }^{139}$ Second, the substitution of generic psychotropics, at least under schemes without the requirement of notification or consent of the consumer or doctor, may infringe on individuals' autonomy in making their own medical decisions. ${ }^{140}$ Third, generic substitution tends not to reflect consumer preferences. In a 2009 survey of 1047 people, researchers found that while a majority of Americans support the idea of generic substitution, $10 \%$ thought that generics caused a greater number of side effects compared to branded drugs, one-third of individuals expressed some degree of discomfort with generic substitution, and only $38 \%$ expressed a personal preference for generics, a result that is contradictory given that a majority reported favoring the idea. ${ }^{141}$ This suggests that Americans may believe that generic drugs are right for others, but not for themselves. This effect is less pronounced in younger, more educated consumers, but is also strongly influenced by the seriousness of the illness being considered, with individuals expressing a greater preference for brand-name drugs for more serious illnesses. ${ }^{142}$

\section{Why Should We Care?}

Though there may be both benefits and detriments to the substitution of generic psychotropics, the detriments outweigh the potential benefits for three reasons. First, some mental illnesses are chronic diseases, meaning that individuals with those disorders who are treated with

139 See supra Part III(A).

140 See infra Part III(C)(3).

${ }^{141}$ Halle Håkonsen \& Else-Lydia Toverud, A Review of Patient Perspectives on Generics Substitution: What are the Challenges for Optimal Drug Use, 1 Generics \& Biosimilars Initiative J. 28, 30 (2012).

142 LaDue, supra note 134, at 713. 
medications will likely face numerous medication decisions in their lifetime. Second, given that medication is a favored treatment for some mental health disorders, medication adherence is a concern and may be negatively impacted by the substitution of generic psychotropics. Third, generic substitution of psychotropic medications may lead to several unanticipated problems, such as difficulty in determining criminal liability under both utilitarian and retributivist theories as well as exposing pharmacists to liability for the potential differential impacts that can arise from generic substitution. Fourth, the recent United States Supreme Court ruling in Mutual Pharmaceutical Co., Inc. v. Bartlett and the Court's holding in PLIVA, Inc. v. Mensing limits the ability of individuals injured by a generic drug to seek remedy. ${ }^{143}$

\section{Mental Health Disorders as Chronic Disorders}

Of the four aforementioned mental disorders, schizophrenia, MDD, and bipolar are viewed as chronic conditions. Roughly $75 \%$ of individuals afflicted with schizophrenia will experience alternating periods of relapse and remission during the course of their lifetime, with full recovery constrained to under one-fifth of cases. ${ }^{144}$ Regarding bipolar disorders, recent research suggests that bipolar manifests itself in a chronic course "characterized by periods of residual symptoms, emotional dysregulation, sleep and circadian rhythm disturbances, cognitive impairment, and increased risk for psychiatric and medical comorbidity between mood episodes." 145 Considering major depressive disorder, research suggests that it is an episodic yet persistent condition, with about three-quarters of individuals who reached clinical levels of depression

143 Mut. Pharm. Co., Inc. v. Bartlett, 133 S. Ct. 2466 (2013); PLIVA, Inc. v. Mensing, 131 S. Ct. 2567 (2011). See infra Part III(C)(5).

144 Alfredo Carlo Altamura et al., Rethinking the Role of LongActing Atypical Antipsychotics in the Community Setting, 27 INT'L CliniCAL PSYCHOPHARMACOLOGY 336, 337 (2012).

145 Marion Leboyer \& David J. Kupfer, Bipolar Disorder: New Perspectives in Health Care and Prevention, 71 J. Clinical PSYCHOLOGY 1689, 1689 (2010). 
reporting that they had experienced multiple depressive episodes. ${ }^{146}$ Given that major depressive disorder, bipolar, and schizophrenia are viewed as chronic disorders and that medication plays a key role in the treatment of all three, care should be taken to provide individuals with these disorders the best and most effective medication. ${ }^{147}$ As indicated previously, for some individuals, generic psychotropic drugs will not fit this bill. ${ }^{148}$

\section{Medication Adherence}

Given that medication is a key part of treatment for schizophrenia, major depressive disorder, and bipolar, medication adherence is essential. Despite its importance, many individuals with mental illness do not comply with their medication regimens; some estimates indicate that as many as half of individuals on medication for psychiatric illness are not fully adherent. ${ }^{149}$ This is problematic, as non-adherence may lead to poor treatment outcomes such as relapse, weakened treatment benefits, and hospitalization. ${ }^{150}$

A number of factors may influence non-adherence. Some non-adherence is related to characteristics of individuals, such as a lack of insight into their disease, forgetfulness, the severity of the illness, experiencing depressive and psychotic symptoms, low cognitive ability, and substance

146 Gavin Andrews, Education and Debate: Should Depression be Managed as a Chronic Disease?, 322 BMJ 419, 419-20 (2001).

147 Nat'l Alliance on Mental Illness, Major Depression Fact Sheet, NAMI 1

(2013), http://www.nami.org/factsheets/depression_factsheet.pdf; Nat'l Alliance on Mental Illness, Bipolar Disorder Fact Sheet, NAMI 1 (2013), http://www.nami.org/factsheets/bipolardisorder_factsheet.pdf; Nat'l Alliance on Mental Illness, Schizophrenia Fact Sheet, NAMI 1 (2013), http://www.nami.org/factsheets/schizophrenia_factsheet.pdf.

148 See supra Part II(A)-(D).

149 Boosting Medication Adherence to Psychotropic Drugs, MPR (Sep. 5, 2013), http://www.empr.com/boosting-medication-adherence-topsychotropic-drugs/article/310444/.

150 Alex J. Mitchell \& Thomas Selmes, Why Don't Patients Take Their Medicine? Reasons and Solutions in Psychiatry, 13 ADVANCES IN PSYCHIATRIC TREATMENT 336, 338 (2007). 
dependency. 151 Some non-adherence stems from the therapeutic alliance, with individuals who perceive their doctor as helpful, trustworthy, and collaborative more likely to be adherent than those who do not perceive their doctor in those ways. ${ }^{152}$ Still other non-adherence may be influenced by external factors, such as stigma, cost, and availability. ${ }^{153}$

However, most important to this Article is that some non-adherence stems from factors having to do with the medications themselves. Research indicates that individuals are less likely to be adherent when they experience adverse side effects from a medication, such as weight gain or sexual dysfunction. ${ }^{154}$ Research also indicates that individuals are more likely to be adherent to a brand name as opposed to a generic medication. ${ }^{155}$ Additionally, medication switching influences adherenceindividuals who notice repeated changes to the shape, color, or packaging of their medications are less likely to be adherent to a medication regimen than those who do not experience such changes. ${ }^{156}$ This influence may be magnified for individuals with psychotic symptoms, who may perceive such changes to be indicative of maltreatment. 157 Given the many reasons individuals may not be adherent to their medication, including brand name medications, it seems foolhardy to compound these reasons by introducing the possible detrimental effects of switching individuals from a brand name to a generic without their consent.

\section{Patient Autonomy: The Right to Medical Decision} Making

In addition to presenting scientific and treatment concerns, generic substitution may present a legal concern

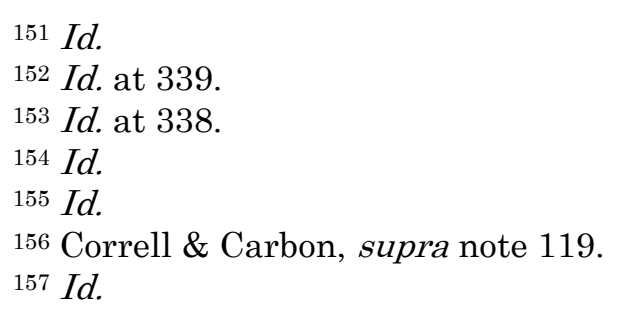


by detrimentally impacting patient autonomy. The right to medical decision making has long been considered a fundamental right, as evidenced in the United States Supreme Court cases of Griswold v. Connecticut, ${ }^{158}$ Roe v. Wade, ${ }^{159}$ and Cruzan v. Director, Missouri Department of Health. ${ }^{160}$ In Griswold, the Court established a penumbral right to privacy that included an inability of the government to restrict a couple's access to contraceptives. ${ }^{161}$ In Roe, a case in which a woman's right to an abortion was disputed, the Court held that abortion was a private medical decision and a fundamental right under the Due Process Clause. ${ }^{162}$

158381 U.S. 479 (1965).

159410 U.S. 113 (1973).

160497 U.S. 261 (1990). A fundamental right is one which is "deeply rooted in [the] Nation's history and tradition" such that it is "implicit in the concept of ordered liberty" and that "neither liberty nor justice would exist if they were sacrificed." Washington v. Glucksburg, 521 U.S. 702, 721 (1997) (quoting respectively Moore v. East Cleveland, 431 U.S. 494, 503 (1977) (plurality opinion); Palko v. Connecticut, 302 U.S. 319, 325-26 (1937)). Fundamental rights can only be restricted when a jurisdiction has a compelling purpose to do so and its scheme is narrowly tailored to the purpose. Reno v. Flores, 507 U.S. 292, 302 (1993).

161 Griswold, 381 U.S. at 484-86. In Griswold, plaintiffs Griswold (Executive Director of Planned Parenthood League of Connecticut) and Buxton (Medical Director of the Planned Parenthood League of Connecticut) were arrested for providing contraceptive counseling to married couples in violation of a Connecticut statute preventing contraception by medical means. Id. at 480 . The Court held the law to be unconstitutional, reasoning that it "operate[d] directly on an intimate relation of husband and wife and their physician's role in one aspect of that relation," that such a relationship fell within the penumbral right to privacy emanating from the First, Third, Fourth, Fifth, and Ninth Amendments, and that the law, in prohibiting the use of contraceptives, swept too broadly and exacted "the maximum destructive impact upon that relationship." Id. at 481-87.

162 Roe, 410 U.S. at 162-67. Roe involved plaintiff Jane Roe (pseudonym), a pregnant woman who desired a legal abortion to terminate her pregnancy. $I d$. at 120 . At the time, abortion was illegal in her home state of Texas unless it was necessary to protect the life of the mother. Id. at 119. Roe argued that Texas's blanket prohibition of abortion in all other instances amounted to an invasion of her penumbral privacy rights stemming from the First, Third, Fourth, Fifth, Ninth, and Fourteenth Amendments, and as such was unconstitutional. $I d$. at 120 . The Court agreed, holding the right to an abortion to be a 
In Cruzan, a case in which a vegetative woman's right to refuse life support was at issue, the Court held that competent individuals have a right to refuse medical treatment if they so choose. ${ }^{163}$

Extending these holdings to generic substitution, taking prescription medication is a private medical decision, much like abortion or contraception. Additionally, much like Cruzan, competent individuals should have the ability to refuse medical treatment, meaning that individuals should have an opportunity to dissent to the substitution of a generic in place of a brand name medication-this is not possible under generic substitution schemes that require no notification or consent. As such, the right of individuals to confer with their doctor and choose which medications they would like to be prescribed should be a fundamental right

fundamental right and that while Texas had some compelling reasons for restricting abortions, such as protecting health and potential life, a blanket prohibition was broad enough that it exceeded the bounds of those compelling interests. $I d$. at 162-67. The Court held similarly in a lesser-recognized companion case to Roe, Doe v. Bolton. Doe v. Bolton, 410 U.S. 179 (1973). Doe involved plaintiff Mary Doe (pseudonym), a married woman who desired the ability to obtain a legal abortion in her home state of Georgia. Id. at 185. At the time, Georgia law prohibited abortion except in cases where it was necessary to save the life of the mother, where the pregnancy was the result of rape, or where the child was at risk of being born with a serious defect or disability; additionally, the statute contained a host of procedural restrictions. Id. at 182-84. Doe alleged that Georgia's prohibition of abortion in all cases not involving these exceptions violated her penumbral privacy rights emanating from the First, Third, Fourth, Fifth, Ninth, and Fourteenth Amendments. Id. at 184-86. Utilizing similar reasoning to Roe, the Court reaffirmed its Roe holding that abortion for women was a fundamental but not absolute right and that numerous of the procedural restrictions on abortion were invalid as being overly broad. Id. at $189-202$.

163 Cruzan, 497 U.S. at 278. Cruzan involved the case of Nancy Cruzan, a woman who had fallen into a vegetative state as a result of injuries sustained in a car accident. Id. at 265-66. Cruzan's parents wanted her removed from life support, but hospital staff refused to do so absent a court order. Id. at 267-68. Although the Court held that individuals did have a fundamental right to refuse life-saving medical treatment, it also upheld a Missouri standard requiring clear and convincing evidence of an incompetent individual's desire to refuse this treatment. Id. at 277-86. 
with which the government, by way of using a pharmacist as a proxy, should not be able to interfere.

In addition to considering the right to medical decision making to be a fundamental right, the Court has held that persons with mental illness have a right not to be coerced into treatment or into taking a medication, as illustrated in the landmark cases of O'Connor V. Donaldson ${ }^{164}$ and Washington $v$. Harper, 165 as well as subsequent decisions such as Perry v. Louisiana, ${ }^{166}$ Riggins v. Nevada, ${ }^{167}$ and Sell V. United States. ${ }^{168}$ In O'Connor v. Donaldson, the Court held that it was unconstitutional to forcibly confine a nondangerous individual with mental illness for the purposes of treatment when he was capable of living in the community either on his own or with assistance. ${ }^{169}$ In Washington $v$. Harper, the Court ruled that the state could forcibly medicate an inmate with antipsychotics, but restricted such forcible medication to situations in which the state had sufficiently shown that the inmate constituted a danger to himself or others and that the medication prescribed was in his best medical interest, indicating a right of nondangerous individuals not to be medicated against their will. ${ }^{170}$

164422 U.S. 563 (1975).

165494 U.S. 210 (1990).

166498 U.S. 38 (1990).

167504 U.S. 127 (1992).

168539 U.S. 166 (2003).

169 Donaldson, 422 U.S. at 576. O'Connor v. Donaldson involved the case of Kenneth Donaldson, a Florida man who had been civilly committed to a mental hospital due to paranoid schizophrenia. Id. at 564-66. Though he posed no danger to himself or to others, J.B. Connor, the hospital superintendent, refused to release Donaldson, deeming that he would be unable to adjust to deinstitutionalized life. Id. at 566-67. However, trial testimony indicated that Donaldson was capable of securing employment outside the hospital setting, and that he had the support of numerous individuals willing to assist him upon his release. Id. at 568 .

170 Harper, 494 U.S. at 233-36. Harper involved the case of Walter Harper, a Washington man convicted of robbery. Id. at 213. While imprisoned, he initially consented to be treated with antipsychotic drugs to treat symptoms of schizophrenia; however, he later withdrew that consent and was medicated against his will. Id. at 214-15. In an earlier case, Vitek v. Jones, the Court held that the involuntary transfer of an 
In Perry v. Louisiana, the Court per curiam vacated a ruling of the Louisiana Supreme Court that authorized the forcible medication of an inmate for the purpose of declaring the inmate competent for execution. ${ }^{171}$ Riggins $v$. Nevada concerned the right of an inmate to refuse medication that would render him competent to stand trial; the Court held that forcible medication for this purpose was unconstitutional under the Due Process Clause unless the state could show that such forcible medication was medically appropriate and that competence could not be restored through less intrusive means. ${ }^{172}$ Last, following the framework set by Riggins, in Sell v. United States the Supreme Court held it to be unconstitutional to forcibly medicate a prisoner for the sake of restoring competence to stand trial unless the medication was in furtherance of an important government interest (to be decided on a case-bycase basis); substantial certainty existed to believe that the medication would render the individual competent without the substantial risk of detrimental side effects; less intrusive alternative measures that could restore competency did not exist; and, that the administration of medication was "medically appropriate." 173

inmate to a state mental hospital for treatment of a mental or disease or defect, absent notice and a hearing, violated a prisoner's Fourteenth Amendment right to due process. 445 U.S. 480, 492-93 (1980).

171 Perry, 498 U.S. 38 (1995).

172 Riggins, 504 U.S. at 133-36. Riggins involved the case of David Riggins, a Nevada man accused of robbery and murder. Id. at 129. While awaiting trial, Riggins complained that he was having auditory hallucinations and was having trouble sleeping, and was prescribed antipsychotics. Id. at 129. Riggins moved for a determination of his competence to stand trial and was found competent; upon this finding, Riggins argued that he wanted to assert an insanity defense against trial, and it was a violation of his Due Process rights to medicate him as it (1) would not allow him to show his natural state at trial and (2) the drug's negative impacts on him would impede his ability to contribute to his defense. Id. at 129-30. The prosecution argued that, since taking him off antipsychotics would render Riggins incompetent to stand trial and Nevada law prohibited the trial of incompetent individuals, Riggins could be compelled to take antipsychotics. Id. at 130 .

173 Sell, 539 U.S. at 180-186. "Medically appropriate" means that, in light of the individual's medical condition, the administration of drugs is in his best medical interests. Id. at 181 . 
In applying these holdings to the issue of generic substitution, the Supreme Court has made it clear that, at least regarding prisoners with mental illness, forcible treatment and medication is to be considered a measure of last resort. This is interesting in light of the Court's holding in Turner V. Safley, which indicated that, given reduced individual liberty and security concerns in prisons, prisons should be given deference in the restriction of prisoners' rights provided that such restrictions were "reasonably related to legitimate penological interests."174 If prisoners, whom the Court has recognized as being subject to liberty and rights restrictions not imposed upon everyday citizens, are not subject to medication against their will except under a strict set of circumstances, why then would it be fair or constitutional to allow individuals who are mentally ill to have a generic drug substituted for a brand name drug when their will regarding such substitution is not known, as in generic substitution schemes that do not involve a consumer's or doctor's notification or consent?

Third, generic substitution may constitute a battery under tort law. Most jurisdictions provide for battery actions for patients who did not consent to a medical treatment. ${ }^{175}$ A majority of jurisdictions allow for patients to recover when they consent to a medical treatment but the physician deliberately deviates from the patient's wishes; additionally, some jurisdictions hold that physicians will be held liable if they provide medical treatment to which a patient has not given express or implied consent. 176

An argument can be made that this conception of medical battery should apply to generic substitution, at least in the abstract. First, although pharmacists are not physicians, they play a role in the treatment process as the gatekeepers of medications. Second, under permissive substitution schemes, pharmacists can exercise their discretion in choosing to fill a patient's prescriptions with a generic, effectively allowing them to make a treatment

174482 U.S. 78, 89 (1987).

175 Nancy J. Moore, Intent and Consent in the Tort of Battery: Confusion and Controversy, 61 AM. U. L. REV. 1585, 1646 (2012).

$176 I d$. at 1648. 
decision for a patient. Third, under a scheme that is both permissive and does not require patient or doctor notification, a pharmacist might ostensibly make a treatment decision but never need to inform the patient, thus never providing the patient an opportunity to render either express or implied consent to the pharmacist. Given the fact that generic substitution may allow for pharmacists to facilitate administration of a treatment without obtaining consent, a pharmacist who decides to substitute a generic drug that has differential effectiveness or detrimental side effects compared to a brand name drug should be liable for battery, at least from a theoretical perspective.

All three of the above issues illustrate potential concerns that may arise when considering the impact of generic substitution on patients' rights to have a voice in their medical treatment. The Supreme Court has long recognized the privacy of individuals' medical decisions with their doctors and the right of individuals not to be medicated without their consent. Ostensibly, tort law should allow for patient recovery if consumers are provided with medication for which they did not consent. Although not all generic substitution schemes are subject to these problems, schemes involving no notification arguably are, and as such should be viewed as a violation of a consumer's right to autonomy in medical decision making.

\section{Seemingly Overlooked Problems: Criminal Culpability and Pharmacist Liability}

Another legal reason for concern regarding generic substitution stems from the seemingly overlooked problems of criminal culpability and pharmacist liability. Considering criminal culpability, so-called "psychotropic defenses" are gaining popularity, as evidenced in both news reports ${ }^{177}$ and in the 2013 film Side Effects. ${ }^{178}$ The defense

\footnotetext{
177 Dan Childs \& Lauren Cox, Did the Drugs Make Him do it? The Zoloft Defense, ABC NEWs (June 4, 2009), http://abcnews.go.com/Health/Sleep/drugs-make-zoloftdefense/story?id=7750816, archived at http://perma.cc/AF6T-CP7F; Colin Poitras, Judge Accepts Prozac Defense, The Courant, Feb. 25,
} 
is predicated on controversial research, which indicates that some psychotropic drugs may spur an adverse reaction in the form of violent behavior. ${ }^{179}$ Although controversial, adverse reactions to psychotropic drugs should diminish culpability, at least theoretically. Under the American system of justice, punishment is justified under two main theories: utilitarianism and retributivism. ${ }^{180}$ Utilitarianism is predicated on the idea that punishment can function as a social good, helping to protect society and offenders through general and specific deterrence, rehabilitation, and isolation. ${ }^{181}$ Retributivism, on the other hand, has its foundation in morality-for justice to be served, a wrongdoer must be punished for his actions. ${ }^{182}$

Applying the principles of punishment to the psychotropic defenses, at least in the context of substitution that requires no notification, under utilitarian rationales individuals' behavior cannot be deterred if it is not a function of their personality but rather a byproduct of a reaction to a medication people did not know that they were taking. Additionally, punishment of an individual claiming a psychotropic defense would not serve the purposes of rehabilitation and isolation-proper rehabilitation in this instance would not be punishment but rather would be switching the individual back to a medication regimen that was tolerable and did not produce the adverse effects that precipitated a crime, thus rendering no need for isolation. Similarly, under a retributivist rationale in which moral wrongdoing is punished, it is hard to see how justice might be served by punishing individuals whose volition may have

2000, http://articles.courant.com/2000-02-25/news/0002250027_1_lymebank-robbery-mental-health, archived at http://perma.cc/AM4-MPPK.

178 SIDE EFFECTS (Open Road Films 2013). For a plot summary of the movie, see Side Effects, IMDB, http://www.imdb.com/title/tt2053463/, archived at $\mathrm{http}: / /$ perma.cc/EC4L-9VHN.

179 Michael Welner et AL., Psychotropic Medications and Crime: The Seasoning of the Prozac Defense, in HANDBOOK OF DRUG INTERACTIONS: A CLINICAL AND FORENSIC GUIDE 635-37 (Ashraf Mozayani \& Lionel P. Raymon eds., 2004).

180 Albin Eser, The Nature and Rationale of Punishment, 28 CARDOZO L. REV. 2427, 2427-29 (2007).

${ }^{181} \mathrm{Id}$.

182 Id. 
been impaired by a drug they did not know they were taking, negating any intention to do wrong.

Another controversial defense that generic substitution may engender is involuntary intoxication. Under common law, a defense of involuntary intoxication may arise when a defendant ingests a substance that induces an adverse reaction that triggers criminal activity, and that substance was ingested due to the negligence or malpractice of a physician or the malevolent intentions of another person. ${ }^{183}$ Though an involuntary intoxication defense usually stems from the ingestion of alcohol or an illegal drug, some courts recognize the defense when the criminal action is precipitated by a wrongly administered medication or by a medication administered correctly but that produced an unexpected effect. ${ }^{184}$ Extended to the example of generic substitution, a medication may be interpreted to be wrongly administered when consumers thought they were taking a brand name medication but in reality were taking a generic. This can also happen when consumers experience adverse reactions to a medication that they did not expect based on their understanding of the brand name medication that they thought they were taking.

A second unanticipated concern is pharmacist liability. Considering that the ability for pharmacists to substitute is granted by the state and states have an incentive to keep drug costs down, it might seem intuitive that pharmacists would be shielded from liability in the event that a generic produced differential effects than associated with a brand name drug. In reality, this is not the case. In a survey of its closed pharmacist liability cases in the United States during a ten-year window from January 1, 2002 to December 31, 2011, the insurance provider CNA/Healthcare Providers Service Organization (HPSO) found that 1.9\% of its wrong drug dispensation cases involved the failure of a pharmacist to verify the equivalency of a generic prior to substitution and that $3 \%$ of its medication mismanagement cases involved the failure of a pharmacist to inform a

183 WELNER, supra note 171 , at 635-37.

$184 \mathrm{Id}$. 
consumer of the change to a generic form of a drug. ${ }^{185}$ Although not constituting a substantial portion of CNA/HPSO closed pharmacist liability cases, these cases indicate that pharmacists do not enjoy absolute immunity from lawsuits and that they should not be surprised if an injured individual takes action against them for the substitution of a generic drug.

\section{Limitation of Remedies for Persons Injured by Generic} Psychotropics and Competitor Liability

A final legal cause for concern regarding generic psychotropics is the lack of a path to recovery for individuals injured by them. ${ }^{186}$ Two recent Supreme Court cases have obscured this path: PLIVA, Inc. V. Mensing 187 and Mutual Pharmaceutical Co., Inc. v. Bartlett. ${ }^{188}$ Mensing arose when two individuals filed suit when they developed tardive dyskinesia after receiving a generic version of Reglan by way of substitution starting in 2001 and 2002.189 The two individuals sought recovery under a theory of failure to warn, claiming that the generic version of Reglan that they were provided did not provide warning that taking the drug for longer could cause tardive dyskinesia. ${ }^{190}$ In 2004, subsequent to Respondents'

185 CNA/Health Providers Service Organization, 2013 Pharmacist Liability: A Ten-Year Analysis, CAN/HPSO 29, 59-60 (2013), https://www.hpso.com/pdfs/db/Pharmacist_Claim_Report_2013.pdf?fileN ame=Pharmacist_Claim_Report_2013.pdf\&folder=pdfs/db\&isLiveStr=Y, archived at http://perma.cc/4RBM-725P (last visited Nov. 23, 2014) (explaining that wrong drug dispensation is a legal claim and medication mismanagement is an ethical claim).

186 Maren Carbon \& Christoph U. Correll, Rational Use of Generic Psychotropic Drugs, 27 CNS DRUGS 353, 355 (2013).

187131 S. Ct. 2567 (2011).

188133 S. Ct. 2466 (2013).

189 Mensing, 131 S. Ct. at 2573. Reglan is a drug used to treat digestive tract problems; tardive dyskinesia is a severe neurological disorder that impacts movement. TD Ctr., Reglan - Side Effects and Withdrawal Symptoms, TD CTR. (last visited Nov. 23, 2014), http://www.tardivedyskinesia.com/reglan/risk-factors/side-effects.php, archived at http://perma.cc/YQ68-ZS3C.

190 Mensing, 131 S. Ct. at 2573. 
development of tardive dyskinesia, branded Reglan's manufacturer requested approval from the FDA to change the drug's warning label to indicate that treatment should not exceed twelve weeks in length. ${ }^{191}$ Ruling on the basis of preemption, the Court held that respondents could not recover under state tort law because for PLIVA to be in compliance with state tort law, it would have to be out of compliance with federal regulations that required generic medications to utilize the same warning labels as their branded counterparts. ${ }^{192}$ In essence, PLIVA did not fail to warn-rather, it was unable to warn. ${ }^{193}$

Similarly, Mutual Pharmaceutical Co., Inc. v. Bartlett arose when Respondent received a prescription for brand name Clinoril to treat shoulder pain, but instead was dispensed a generic version. 194 Shortly after receiving the generic, Respondent, a resident of New Hampshire, became afflicted with an acute case of toxic epidermal necrolysis that disfigured, disabled, and nearly blinded her. ${ }^{195}$ At the time, Clinoril did not have a warning label apprising consumers of the possibility of toxic epidermal necrolysis. ${ }^{196}$ Respondent filed suit under theories of design-defect and failure to warn, claiming that New Hampshire law required drug manufacturers to ensure the safety of the design of their product, which could be established by way of adequate warning about a drug's potential hazardous effects. ${ }^{197}$ Relying on its holding in Mensing, the Court again held that federal regulations requiring generic drugs to employ the same warning labels as their branded counterparts preempted stated law, and that Mutual could not have changed its warning labels to address the

191 Id. at $2572-73$.

192 Id. at $2577-78$.

193 Id.

194 Mut. Pharm. Co., Inc. v. Bartlett, 133 S. Ct. 2466, 2472 (2013). Clinoril is a non-steroidal anti-inflammatory (NSAID). Merck \& Co., Inc., Tablets: Clinoril $($ Sulindac), MERCK, https://www.merck.com/product/usa/pi_circulars/c/clinoril/clinoril_pi.pdf (last visited Nov. 23, 2014), archived at http://perma.cc/HG4A-2WZ9.

195 Bartlett, 133 S. Ct. at 2472.

${ }^{196} \mathrm{Id}$

197 Id. 
possibility of toxic epidermal necrolysis and still be in compliance with federal regulations. ${ }^{198}$

Mensing and Bartlett effectively barred injured consumers from asserting a failure to warn claim against a generic drug manufacturer as the generic manufacturer is reliant upon branded drug manufacturers in terms of what can be put on a warning label; this bar significantly limits the paths to recovery for individuals harmed by generics. 199 However, a potential - though controversial - route around the preemption issue could be to sue the branded company when a consumer is injured by a generic drug under competitor liability. ${ }^{200}$ Applied in this context, competitor liability asserts that brand name manufacturers should be held liable for adverse reactions to generic versions of the drug under theories of negligent misrepresentation and fraud, arguing that due to federal labeling regulations, it is "eminently foreseeable" that a physician may prescribe a generic version of a medication while relying on the warning label of a branded medication. ${ }^{201}$ Though this is a very small minority approach, 202 it is indicative of savvy lawyers potentially raising the issue in the future as a way to navigate around Mensing and Bartlett when clients are injured by psychotropic medications.

198 Id. at 2479.

199 Carbon \& Correll, supra note 184, at 355.

200 Victor E. Schwartz et al., Warning: Shifting Liability to Manufacturers of Brand-Name Medicines When the Harm Was Allegedly Caused by Generic Drugs has Severe Side Effects, 81 FORDHAM L. REV. 1835, 1849-53 (2013).

201 Id. at 1851.

202 Though a very small minority approach, several jurisdictions have allowed a plaintiff to succeed under a theory of duty due to foreseeability: California (Conte v. Wyeth, Inc.), the United States Court for the District of Vermont (Kellogg $v$. Wyeth), and the United States Court for the Northern District of Illinois (Dolin v. SmithKline Beecham Corp.). Conte v. Wyeth, Inc., 85 Cal. Rptr. 3d 299, 320-21 (Cal. Ct. App., 2008); Kellogg v. Wyeth, 762 F. Supp. 2d 694, 708-09 (D. Vt., 2010); Dolin v. SmithKline Beecham Corp., No. 12 C 6403, 2014 U.S. Dist. LEXIS 26219, at *16-20 (N.D. Ill., Feb. 28, 2014). 


\section{What SHOULD We Do?}

The previous three sections established that generic substitution is a prevalent practice, that generic psychotropics may not always perform equivalently to branded drugs, and that there are a host of legitimate reasons to be concerned about generic substitution schemes as they apply to people in general and specifically to individuals with mental illness. It would be impractical to think that generic substitution could be abolished. As such, this section will provide several brief suggestions for reform to mitigate some of the issues surrounding generic substitution of psychotropic medications.

\section{A. Eliminate Mandatory Generic Substitution}

Mandatory generic substitution is the most coercive form of substitution in that it does not allow for discretion on the part of pharmacists, physicians, or consumers. This is exacerbated in a scheme that provides for both mandatory substitution and does not require consent or notification-in these instances, consumers do not even realistically have a choice to not take the drug as they may have no knowledge that they have been switched to a generic until they experiences some type of adverse consequence. By allowing for at least the discretion of pharmacists who could face liability if they do not verify the equivalence of a generic to a branded drug, at least one (albeit limited) safeguard is placed against the dispensation of a potentially less effective or even harmful generic psychotropic drug.

\section{B. Notification and Consent}

Another potential solution is to require that all substitution schemes require either consent or notification of patients or their physicians before substitution can take place. In permissive schemes, obtaining consent from either patients or physicians places autonomy back in the hands of patients and their doctors by allowing them to choose if they are comfortable with substitution, consistent with 
aforementioned constitutional and common law ideals regarding medical decision making. ${ }^{203}$ While requiring notification does not return the same degree of autonomy to a patient as consent, it does at least allow a doctor to cancel or change a prescription or for a patient to consult with her doctor or decide against taking the generic.

\section{Education}

In conjunction with the above, educating consumers about generic drugs may help consumers to make informed decisions about whether they are comfortable taking a generic drug. Further, education may help dispel myths and alleviate anxiety about taking generic drugs, which is desirable in maintaining similar levels of generic substitution as the ones that currently exist. In a study on the effect of patient education intervention on the acceptance of generic drugs, John-Antoni Valles and his research team found that over $98 \%$ of patients exposed to an education intervention later agreed to receive a generic formulation as compared to a branded one. ${ }^{204}$ Further, the intervention merely consisted of verbal information and handout materials about the advantages and disadvantages of both generic and branded drugs, suggesting that the acceptance of generic drugs can be obtained with relatively little effort. ${ }^{205}$

\section{At the Very Least, Employ the Above Proposals for Psychotropic Drugs}

Though the above solutions would be preferable as they would impact all consumers, in the event that the above proposals prove undesirable for the general population, they should at least be provided to individuals taking psychotropic medications, given the specialized concerns of

203 See supra Part III(C)(3).

204 Joan-Antoni Vallès et al., A Prospective Multicenter Study of the Effect of Patient Education on Acceptability of Generic Prescribing in General Practice, 65 HEALTH POL'Y 269, 272 (2003).

205 Id 
generic substitution with a mentally ill population illustrated in Part II of this Article.

\section{CONCLUSION}

Every state provides for generic substitution either permissively at a pharmacist's discretion or as mandated by law. Though states approach the concept of generic substitution in a variety of ways, mandating the substitution of generic for brand name drugs and lacking a requirement for patient/physician consent are particularly deleterious approaches. An approach utilizing both of these schemes seems paternalistic.

Although generic substitution provides an economic benefit to consumers, it is scientifically misguided. Though numerous generic versions of medications exist, and though these generics are considered to be "bioequivalent," the concept of bioequivalence is predicated upon a faulty assumption that similar bioavailability between generic and branded drugs yields similar treatment outcomes. Further, the pharmacokinetic studies by which bioequivalence is determined are inherently flawed. These studies utilize homogenous samples of healthy, young males who are likely not representative of the population the test generic is supposed to serve, and employ a single-dose administration that is not reflective of the way that medications are taken in the real world.

Generic substitution may also give rise to specialized concerns regarding the treatment of mental health disorders. Research suggests that for bioequivalent psychotropic medications, though some generic formulations may prove to be similarly effective to brand name medications, many generic formulations of psychotropic medications exhibit inferior performance in comparison to their branded counterparts as well as produce uncomfortable or hazardous side effects that may discourage medication adherence, an integral facet in the treatment of mental illness. This is especially alarming given that rates of treatment compliance for individuals with mental illnesses are already low, and that relapse 
rates for this population are high. Further, though failed treatments for both physical and mental illness may cast a financial burden on society, failed treatment of mental disorders may elicit some unforeseen problems, such as determining culpability for individuals who commit crime while unwittingly taking a generic as opposed to a more effective branded medication, as well as determining tort liability in cases where failed psychotropic medications injure consumers.

Generic substitution also undermines consumer autonomy. First, it can disrupt patients' right to make their own medical decisions, a right reflected by the tort concept of medical battery as well as a right championed in such Supreme Court cases as: Cruzan v. Director, Missouri Department of Health, Griswold v. Connecticut, Roe v. Wade, O'Connor v. Donaldson, Perry v. Louisiana, Riggins $v$. Nevada, Sell v. United States, and Washington v. Harper. 206 Second, it may undermine patient autonomy by not reflecting the medication preferences of the American public. Although it favors the general concept of generic substitution, it does not endorse a personal preference for generic medications.

To respect patient autonomy in medical decision making, ensure the maximum effectiveness of psychotropic medications, and manage deleterious social behaviors by individuals with mental illnesses, mandatory generic substitution of psychotropic drugs should be prohibited. Additionally, though generics may be substituted permissively, pharmacists should always be required to obtain patient consent before substituting, and patients should be educated about the similarities and differences 
